\title{
Hydrobiologia \\ Heat waves trigger swift changes in the diet and life-history of a freshwater snail --Manuscript Draft--
}

\begin{tabular}{|c|c|c|}
\hline \multicolumn{3}{|l|}{ Manuscript Number: } \\
\hline Full Title: & \multicolumn{2}{|c|}{ Heat waves trigger swift changes in the diet and life-history of a freshwater snail } \\
\hline Article Type: & \multicolumn{2}{|l|}{ Primary research paper } \\
\hline Keywords: & \multicolumn{2}{|c|}{$\begin{array}{l}\text { climate change; diet selection; extreme climatic events; herbivory; Radix balthica; } \\
\text { stable isotopes }\end{array}$} \\
\hline Corresponding Author: & \multicolumn{2}{|l|}{$\begin{array}{l}\text { Bruno Martins Carreira } \\
\text { PORTUGAL }\end{array}$} \\
\hline \multicolumn{3}{|c|}{$\begin{array}{l}\text { Corresponding Author Secondary } \\
\text { Information: }\end{array}$} \\
\hline \multicolumn{3}{|c|}{ Corresponding Author's Institution: } \\
\hline \multicolumn{3}{|c|}{$\begin{array}{l}\text { Corresponding Author's Secondary } \\
\text { Institution: }\end{array}$} \\
\hline First Author: & \multicolumn{2}{|l|}{ Bruno Martins Carreira } \\
\hline \multicolumn{3}{|c|}{ First Author Secondary Information: } \\
\hline \multirow[t]{4}{*}{ Order of Authors: } & \multicolumn{2}{|l|}{ Bruno Martins Carreira } \\
\hline & \multicolumn{2}{|l|}{ Pedro Segurado } \\
\hline & \multicolumn{2}{|l|}{ Anssi Laurila } \\
\hline & \multicolumn{2}{|l|}{ Rui Rebelo } \\
\hline \multicolumn{3}{|c|}{ Order of Authors Secondary Information: } \\
\hline \multirow[t]{6}{*}{ Funding Information: } & $\begin{array}{l}\text { Fundação para a Ciência e a Tecnologia } \\
\text { (EXPL_BIA-ANM_0932_2012) }\end{array}$ & Assistant Professor Rui Rebelo \\
\hline & $\begin{array}{l}\text { Fundação para a Ciência e a Tecnologia } \\
\text { (SFRH/BD/80341/2011) }\end{array}$ & Dr. Bruno Martins Carreira \\
\hline & $\begin{array}{l}\text { Fundação para a Ciência e a Tecnologia } \\
\text { (IF/01304/2015) }\end{array}$ & Associate Professor Pedro Segurado \\
\hline & $\begin{array}{l}\text { Fundação para a Ciência e a Tecnologia } \\
\text { (UID/AGR/00239/2013) }\end{array}$ & Not applicable \\
\hline & $\begin{array}{l}\text { Ministerstvo Školství, Mládeže a } \\
\text { Tělovýchovy } \\
\text { (LM2015075) }\end{array}$ & Not applicable \\
\hline & $\begin{array}{l}\text { Ministerstvo Školství, Mládeže a } \\
\text { Tělovýchovy } \\
\text { (EF16 013/0001782 - SoWa Ecosystems } \\
\text { Research) }\end{array}$ & Not applicable \\
\hline Abstract: & \multicolumn{2}{|c|}{$\begin{array}{l}\text { Extreme climatic events, such as heat waves, may induce changes in nutrient } \\
\text { acquisition by omnivorous ectotherms. Likely modulated by the intensity, frequency } \\
\text { and duration of these pulse events, dietary shifts may threaten the stability of } \\
\text { freshwaters. We investigated the effects of heat wave duration on diet assimilation and } \\
\text { life-history traits of the freshwater gastropod Radix balthica. We compared the } \\
\text { magnitude of the effects of a short (one week) and a long heat wave (seven weeks) on } \\
\text { the assimilation of animal and plant-based diets, measuring performance in terms of } \\
\text { growth rate and reproduction. We hypothesized that heat waves should increase the } \\
\text { proportion of plant material assimilated on the mixed diet and change the performance } \\
\text { of snails on the animal and plant-based diets. Both heat waves increased the } \\
\text { assimilation of plant material on the mixed diet and growth rate, with minor negative } \\
\text { effects on reproduction. However, responses were disproportional to heat wave } \\
\text { duration, as the short heat elicited swift and relatively stronger responses. Our findings } \\
\text { showcase the role of phenotypic plasticity in aiding ectotherms to cope with increased }\end{array}$} \\
\hline
\end{tabular}


thermal stress and acclimate. Temporarily changing the strength of trophic interactions, dietary shifts during heat waves may alter community dynamics in freshwater habitats.

Suggested Reviewers:

Otto Seppälä

otto.seppaelae@eawag.ch

Co-author in publications by Katja Leicht on the effects of heat waves in a freshwater snail and very likely a reviewer of an earlier version of the manuscript submitted to Biology Letters. Katja Leicht has no online presence.

Kwang Pum Lee

Seoul National University College of Agriculture and Life Sciences

kwanglee@snu.ac.kr

Relevant publications on the topic of temperature and nutrient interactive effects on ectotherms.

Peiyu Zhang

p.zhang@nioo.knaw.nl

Previous publications on temperature and nutrient interactive effects on freshwater snails. 
2

3

4

5

$6 \quad{ }^{1} \mathrm{cE} 3 \mathrm{c}-$ Centre for Ecology, Evolution and Environmental Changes, Faculdade de

7 Ciências da Universidade de Lisboa, Bloco C2, Campo Grande, 1749-016 Lisboa,

8 Portugal

$9{ }^{2}$ Animal Ecology/ Department of Ecology and Genetics, Uppsala University,

10 Norbyvägen 18D, 75236 Uppsala, Sweden

$11{ }^{3}$ University of South Bohemia, Faculty of Science, Department of Ecosystem

12 Biology and Soil and Water Research Infrastructure, Branišovská 1760,

1337005 České Budějovice, Czech Republic

$14{ }^{4}$ Centro de Estudos Florestais, Instituto Superior de Agronomia, Universidade de

15 Lisboa, 1349-017 Lisboa, Portugal

16

$17{ }^{*}$ Corresponding author

18 E-mail: bmcarreira@,fc.ul.pt

19 Phone: +351217500000, ext 2256517

20

Fax: +351217500028 
ABSTRACT

Extreme climatic events, such as heat waves, may induce changes in nutrient acquisition by omnivorous ectotherms. Likely modulated by the intensity, frequency and duration of these pulse events, dietary shifts may threaten the stability of freshwaters. We investigated the effects of heat wave duration on diet assimilation and life-history traits of the freshwater gastropod Radix balthica. We compared the magnitude of the effects of a short (one week) and a long heat wave (seven weeks) on the assimilation of animal and plant-based diets, measuring performance in terms of growth rate and reproduction. We hypothesized that heat waves should increase the proportion of plant material assimilated on the mixed diet and change the performance of snails on the animal and plant-based diets. Both heat waves increased the assimilation of plant material on the mixed diet and growth rate, with minor negative effects on reproduction. However, responses were disproportional to heat wave duration, as the short heat elicited swift and relatively stronger responses. Our findings showcase the role of phenotypic plasticity in aiding ectotherms to cope with increased thermal stress and acclimate. Temporarily changing the strength of trophic interactions, dietary shifts during heat waves may alter community dynamics in freshwater habitats.

\section{KEYWORDS} climate change, diet selection, extreme climatic event, Radix balthica, stable isotopes 
The climatic changes projected under the most recent scenarios demand a better

understanding of the ecological responses to global warming and extreme climatic events, especially in organisms such as ectotherms (Stoks et al., 2017). Temperature governs many physiological and ecological processes (Gillooly et al., 2001; Angilletta, 2009), and there is a growing interest for its effects on nutrient acquisition. Changes in nutrient acquisition mediated by temperature may affect consumer interactions with both resources and other consumers, which may threaten the stability of ecosystems (Boukal et al., 2019). Freshwater communities are disproportionally at risk (Parmesan, 2006; Woodward et al., 2010), as they are mainly composed of ectotherms with a temperaturedependent metabolism (Parmesan \& Yohe, 2003; Clusella-Trullas et al., 2011; Paaijmans et al., 2013). Studying temperature and nutrient interactions across organization levels will be a critical step to develop realistic predictions of the ecological responses to global changes (Cross et al., 2015; Kutz et al., 2019).

Two hypotheses link temperature, food quality (i.e. C:N:P nutrient ratios) and diet selection. The Growth Rate Hypothesis (Elser et al., 1996) predicts that higher temperatures increase phosphorous and nitrogen demand, needed to sustain increased growth (Persson et al., 2011) and protein turnover rates (Lemoine et al., 2013). In contrast, the Respiration Hypothesis predicts that higher temperatures increase the relative demand for carbon over nitrogen or phosphorus (Cross et al., 2015), as the stronger effect of temperature on catabolism than on anabolism promotes a greater increase in respiration than in growth (Karl \& Fischer, 2008; Forster et al., 2011). Consequently, under higher temperatures ectotherms require extra carbon in their diet (Acheampong et al., 2014) and may select for increasingly carbon-rich foods (Anderson et al., 2017), which should better compensate for the energetic deficit induced by warming (Kingsolver \& Woods, 1997; 
67 Lemoine \& Burkepile, 2012). Additionally, temperature may influence nutrient acquisition through different scaling effects on other metabolic processes. For instance, higher temperatures promote a greater increase in feeding and gut passage rates than in assimilation rates (Seifert et al., 2014), and this imbalance may increase the assimilation efficiency of carbohydrates (Croll \& Watts, 2004).

Phenotypic plasticity is an ubiquitous response to different environmental conditions (Ghalambor et al., 2007), and dietary shifts may constitute an important aspect of the plastic responses to different temperatures. Supporting increased herbivory at higher temperatures, dietary shifts have been documented experimentally in several arthropod taxa - copepods (Boersma et al., 2016; Malzahn et al., 2016), decapods (Carreira et al., 2017) and insects (Lee \& Roh, 2010; Clissold et al., 2013; Lee et al., 2015; Rho \& Lee, 2017; Rendon et al., 2019); in anuran larvae (Carreira et al., 2016); and in fish (Emde et al., 2016; Vejř́iková et al., 2016). These findings agree with the higher prevalence of herbivory in fish communities of warmer waters (Floeter et al., 2005; Jeppesen et al., 2010; González-Bergonzoni et al., 2012) and with the seasonal increases in fish herbivory during summer (Guinan Jr et al., 2015; González-Bergonzoni et al., 2016). However, other studies have reported opposite effects showing a greater protein intake at higher temperatures (Lemoine et al., 2013; Schmitz et al., 2016), contextdependent temperature effects on nutritional requirements (Anderson et al., 2017), and no temperature effects on feeding preferences (Miller et al., 2009; Zhang et al., 2018a). As such, the potential for temperature to change nutritional requirements and for warming to increase herbivory is still under debate (Anderson et al., 2017; Carreira, 2017). More studies are required to understand how temperature mediates changes in nutrient acquisition in ectotherms and the extent to which this link may impact ecological communities (Rosenblatt \& Schmitz, 2016; Rho \& Lee, 2017). 

stochastic perturbations, which can act as a major selective force shaping population dynamics and species interactions (Parmesan, 2006; Walther, 2010; Palmer et al., 2017). Recent work showed omnivorous ectotherms to increase the assimilation of plant diets during heat waves (Carreira et al., 2016, 2017), suggesting that these organisms optimized energy intake at higher temperatures by avoiding protein-rich diets. In natural systems, dietary shifts in response to heat waves may prove disruptive, temporarily changing the strength of trophic interactions and even the predominant impacts of invasive alien species (Carreira et al., 2017). The severity of heat wave effects on organisms and communities depends on their intensity, frequency and duration (Mironidis \& Savopoulou-Soultani, 2010; Dowd et al., 2015). Likewise, these properties may also dictate the magnitude of the dietary shifts observed during heat waves and, in turn, the magnitude of their impacts on species functional roles and species interactions. Even related traits of Radix balthica (Linnaeus, 1758). Widespread throughout freshwater habitats in Europe and Asia, this hermaphroditic pulmonate gastropod is common in the Iberian Peninsula (Pfenninger et al., 2011), where it regularly experiences heat waves. We aimed to investigate both the effects of currently commonly occurring short heat waves, as well as the effects of uncommonly long heat waves, expected to become more 114 frequent in the future (Meehl \& Tebaldi, 2004; Diffenbaugh \& Field, 2013). For this, snails were fed animal, plant or mixed diets and exposed to simulated heat waves for a short duration (one week) or a long duration (seven weeks). Performance was measured 
117 in terms of growth rate and reproduction, and the proportion of animal and plant material assimilated by snails on the mixed diet was estimated using stable isotope mixing models. We predicted that heat waves effects should: 1) increase the assimilation of plant material by snails on the mixed diet; 2) change the relative performance of snails on the animal and plant diets; and 3) be proportional to heat wave duration.

\section{METHODS}

Heat wave characterization in the study area

The severity of heat waves has increased globally since 1950 (Perkins et al., 2012).

Climatic models project an increase in their frequency of occurrence (up to $31 \%$ ) and average duration (up to $35 \%$ ), as well as greater positive anomalies (over $3^{\circ} \mathrm{C}$ ) especially in the areas currently most susceptible, like the Mediterranean basin (Easterling, 2000; Meehl \& Tebaldi, 2004). Furthermore, there is a dramatic increase in the likelihood of statistically unlikely extreme events (Dasari et al., 2014), such as the one that afflicted Europe in 2003 (Christidis et al., 2015). Following global trends, the Iberian Peninsula (Western Europe) experienced an increase in mean temperature during the latter half of 20th century, especially marked in early summer (Dasari et al., 2014). During the 21 st century, the mean annual temperature in this climate change hotspot is expected to increase up to $6^{\circ} \mathrm{C}$ (Giorgi, 2006; Jerez et al., 2013).

Heat waves are considered to occur when the daily maximum temperature exceeds the average maximum temperature by $5^{\circ} \mathrm{C}$ for more than five consecutive days, the reference period being 1961-1990 (Frich et al., 2002). In the southwest of Portugal, heat waves occur frequently during spring, when the larval and adult stages of many ectotherm species complete their life cycle in Mediterranean temporary ponds, before pond drying in the summer. Using a 10-year data set of air temperatures recorded during the period of 
2002-2012, we characterized the most common spring heat waves occurring in southwestern Portugal. Typically, this region is afflicted by a heat wave in the end of April which lasts on average $7.8 \pm 1.3$ days and is often followed by another heat wave in mid-May lasting on average $7.5 \pm 1.3$ days (B. M. Carreira, unpubl. data 2002-2012). A five-year survey carried out in 42 temporary ponds located in southwestern Portugal during April and May revealed that at this time water temperatures ranged from 17 to $25^{\circ} \mathrm{C}$ with an average temperature of $20^{\circ} \mathrm{C}$ (R. Rebelo, unpubl. data 2010-2014).

\section{Experimental setup and procedures}

Young adult individuals of Radix balthica $(10.5 \pm 1.4 \mathrm{~mm} ; \mathrm{N}=200)$ were collected in southwestern Portugal (3847'30.6' 'N, 9²5'9.0' W) on 18 April 2014. The snails were brought to the facilities at the University of Lisbon and kept in an experimental room at $20^{\circ} \mathrm{C}$ in $15 \mathrm{~L}$ aquaria (ca. 25 snails per aquarium) under 12L:12D photoperiod. To ensure standardized isotopic signatures, snails were maintained in these conditions for a month, while being fed ad libitum commercial fish food (Pond Sticks, CTetra) every two days along with water change.

At the start of the experiment, snails were blotted dry in paper towel, weighed to nearest $0.1 \mathrm{mg}$, and photographed for determination of initial body size (using ImageJ software). Snails were then transferred individually to $80 \mathrm{~mL}$ mesh-covered cups and placed in water baths. We followed a fully factorial experimental design with diet (three levels) and temperature (three levels) as factors and assigned 18 randomly selected snails to each treatment combination. While subject to the experimental treatments, snails produced egg clutches that were removed along with feeding and water renewal every two days. The position of the snails in the water baths within a given treatment was 
recorded. Water bath temperatures were checked daily and adjusted when necessary. The experiment ended after 49 days, when snails were blotted dry in paper towel, weighed, photographed and euthanized by rapid freezing at $-18^{\circ} \mathrm{C}$.

The snails were fed one of three experimental diets offered ad libitum: Animal $\operatorname{diet}(\mathrm{A})$ - defrosted Chironomidae larvae; Plant diet (P) - defrosted spinach leaves; Mixed diet $(\mathrm{M})$ - both food items in diets $\mathrm{A}$ and $\mathrm{P}$ offered ad libitum in similar proportions of fresh weight. These food items were obtained commercially and selected based on previous experimental studies on $R$. balthica (Johansson et al., 2016). The food items complied with the basic assumptions that the animal diet was protein-rich and the plant diet protein-poor, and that both food items had distinct isotopic signatures and $\mathrm{C}: \mathrm{N}$ ratios (Table 1).

Snails experienced one of three temperature treatments (Fig. 1): No Heat Wave (NHW) - constant temperature of $20^{\circ} \mathrm{C}$ for seven weeks; Short Heat Wave (SHW) constant temperature of $20^{\circ} \mathrm{C}$ for six weeks followed by one week at $25^{\circ} \mathrm{C}$; Long Heat Wave (LHW) - constant temperature of $25^{\circ} \mathrm{C}$ for seven weeks. The range of temperatures experienced by the snails in the experimental treatments was selected to match the water temperatures recorded in temporary ponds during spring. The duration of the short heat wave aimed to simulate current spring heat waves in the southwest of Portugal (ca. one week). Like in (Roth et al., 2010), the duration of the long heat wave aimed to simulate unusually long heat waves, such as the one that afflicted Europe in 2003 for nearly 50 days (Schär et al., 2004), which are expected to become more frequent in the future (Meehl \& Tebaldi, 2004; Diffenbaugh \& Field, 2013).

\section{Stable isotope analysis}


A subsample of 9 snails per treatment was randomly selected for stable isotope analysis. After shell removal, the muscle tissue of each snail was dried at $60^{\circ} \mathrm{C}$ for $24 \mathrm{~h}$ and ground to a fine powder with mortar and pestle. The samples were cleansed of storage lipids with chloroform-methanol (2:1; Dobush et al., 1985), and then re-dried at $60^{\circ} \mathrm{C}$ for 24h. Stable isotope ratios $\left({ }^{13} \mathrm{C} /{ }^{12} \mathrm{C} ;{ }^{15} \mathrm{~N} /{ }^{14} \mathrm{~N}\right)$ and elemental analyses $(\mathrm{C}: \mathrm{N})$ were determined by continuous flow isotope mass spectrometry (CF-IRMS) (Preston \& Owens, 1983), on a Hydra 20-22 (Sercon, UK) stable isotope ratio mass spectrometer, coupled to a EuroEA (EuroVector, Italy) elemental analyser for online sample preparation by Dumas-combustion. The standards used were IAEA-CH6 and IAEA-CH7 for carbon isotope ratio, and IAEA-N1 and USGS-35 for nitrogen isotope ratio; $\delta^{13} \mathrm{C}$ results were referred to PeeDee Belemnite (PDB) and $\delta^{15} \mathrm{~N}$ to Air. Precision of the isotope ratio analysis was $\leq 0.2 \%$ ( 6 to 9 replicates of laboratory standards in every batch).

\section{Statistical analyses}

Time-integrated estimates of the dietary choices of the snails maintained on the mixed diet were obtained with stable isotope mixing models. Using the Stable Isotope Analysis in R package (SIAR; Parnell et al., 2013), we fit a Bayesian model to the proportions of animal and plant material contributing to the isotopic signature of the snails on the mixed diet. The resulting probability distribution functions (10.000 iterations) for the proportions of the two sources assimilated by these consumers incorporated variability in the sources, trophic enrichment factors and elemental composition (Parnell et al., 2010). Following standard procedures, we specified the isotopic signatures and C:N ratios of the food items, building a model for each temperature treatment. We accounted for the variability in the trophic enrichment factors across sources by using the isotopic signatures of the snails fed on the single diets (animal or plant) at each temperature. The 
216 food items differed considerably in their $\mathrm{C}: \mathrm{N}$ ratio and more than $2 \%$ in the isotopic 217 signature of both isotopes (Table 1). Based on the data obtained by (Thomas \& Crowther, 218 2015), we estimated the half-life for ${ }^{13} \mathrm{C}$ and ${ }^{15} \mathrm{~N}$ turnover rates of the snails on the mixed diet (body weight: $167.6 \pm 48.9 \mathrm{mg}$ ) as ca. 13 days.

Treatment effects on snail growth rate, calculated as ln of daily weight increase (mg), were tested with a general linear model in the software STATISTICA 12.6.255.0 (StatSoft 2012). Treatment effects on the total number of oviposited eggs were tested with a generalized linear model specifying a negative binomial distribution with a log link function in the software SPSS 24 (IBM). Initial shell length $(10.5 \pm 1.4 \mathrm{~mm}$; defined as the distance between the apex and the edge of the outer shell lip) was included as a covariate in both models. Post hoc pairwise comparisons were corrected for multiple comparisons with Bonferroni test.

\section{RESULTS}

Regardless of the temperature treatment, plant material contributed two times more to the isotopic signature of $R$. balthica than animal material - the overall median proportion of plant material assimilated by snails on the mixed diet averaged 0.69 . The median proportion of plant material assimilated increased from 0.59 in NHW (Bayesian credible interval $(\mathrm{BCI})=0.34-0.81)$ to 0.70 in $\mathrm{SHW}(\mathrm{BCI}=0.52-0.85)$ and to 0.78 in LHW (BCI $=0.63-0.89)$ (Fig. 2a). In other terms, relative to NHW, the median proportion of plant material assimilated by snails on the mixed diet increased by 0.11 at the end of SHW and by 0.19 at the end of LHW. These effects were non-linear and, relative to heat wave duration, the snail's response in SHW was four times greater than in LHW. In other terms, the increment in the proportion of plant material assimilated by snails at the end of SHW corresponded to $58 \%$ of that of snails at the end of LHW. 

greater than on the animal diet (Table 2; Fig. 2b). The growth rate in LHW was two times greater than in NHW $(P<0.001)$ and $24 \%$ greater than in SHW $(P<0.001)$, while the growth rates in NHW and SHW were not significantly different (Table 2; Fig. 2b). Effects on the growth rate of $R$. balthica were non-linear and, relative to heat wave duration, the response to SHW was four times greater than to LHW. Overall, the increase in snail growth rate triggered by the one-week heat wave (SHW) corresponded to $59 \%$ of that triggered by the seven-week heat wave (LHW). This strong disproportion in the snail's response to heat wave effects in SHW and LHW was also verified in the snails on the mixed diet and its magnitude was comparable (61\%). We found no significant effects of diet $\times$ temperature interactions on snail growth (Table 2; Fig. 2b).

We found a positive relationship between reproduction (total number of eggs produced $)$ and shell length at the end of the experiment $(\mathrm{r}=0.387 ; \mathrm{P}<0.01)$. Reproduction on the plant diet was over two times greater than on the animal diet, but not significantly greater than on the mixed diet (Table 2; Fig. 2c). Temperature had no significant main factor effect on reproduction (Table 2; Fig. 2c), even though the mean number of eggs laid per individual decreased from 59 in NHW to 47 in SHW and to 30 eggs in LHW. Relative to heat wave duration, the reduction in reproduction observed in SHW was three times greater than in LHW, corresponding to $41 \%$ of the reduction observed in LHW. We found diet $\times$ temperature interactions indicating that: i) on the plant diet, reproduction in NHW and LHW was greater than in SHW $(P<0.001)$, unlike on the animal diet $(P$ $=0.531)$ and on the mixed diet $(P=0.633)$; ii) in SHW, there was no diet effect on reproduction $(P=0.113)$, unlike in NHW $(P<0.05)$ and LHW $(P<0.01)$ (Table 2; Fig. plant diet in the SHW treatment $\left(\mathrm{X}^{2}=9.186 ; \mathrm{P}<0.01\right)$. While egg production on plant 
266 diet by the animals that oviposited was similar in all temperature treatments, the 267 proportion of snails that oviposited in SHW (46\%) was half of the proportion of the snails that oviposited in NHW (91\%) and LHW (100\%).

\section{DISCUSSION}

Previous studies reported heat waves effects on the survival (Garrabou et al., 2009) and internal resource budgets of organisms, leading to changes in life history traits (Jiguet et al., 2007; Chiu et al., 2014; Fischer et al., 2014; Dinh et al., 2016; Arambourou et al., 2017). We investigated the expression of phenotypic plasticity in function of heat wave duration, comparing the magnitude of the effects of short- and long-lasting heat waves on the diet and life history traits of a freshwater gastropod. Although both types of heat wave increased the assimilation of plant material and the growth rate of $R$. balthica, with minor costs in reproductive output, the magnitude of the responses was disproportional to heat wave duration. Our results revealed a steep thermal reaction norm and suggest that organisms may be unable to sustain the magnitude of short-term responses over long periods. The strong responses deployed by $R$. balthica under the relatively short exposure to high temperatures showcase the major role of phenotypic plasticity as an important mechanism aiding ectotherms to cope with heat waves. Furthermore, presenting the first evidence for temperature-induced dietary shifts in gastropods, our findings add to those obtained in other taxa, supporting a general temperature effect on nutrient acquisition in omnivorous ectotherms and warming to increase herbivory. 
Snails on the mixed diet increased the assimilation of plant material under the heat waves, in agreement with the findings of other studies in omnivorous ectotherms (Lee et al., 2015; Boersma et al., 2016; Carreira et al., 2016, 2017). Supporting the Respiration Hypothesis (Cross et al., 2015), R. balthica used trophic plasticity to increase the relative assimilation of carbon at higher temperatures. The assimilation shifts in SHW (11\%) and LHW (19\%) are similar to those reported in tadpoles (Carreira et al., 2016) and crayfish (Carreira et al., 2017) under short heat waves (5-11\%) and long heat waves (22\%). However, the magnitude of the responses displayed may be partially driven by the difference in the $\mathrm{C}: \mathrm{N}$ ratios of the food items available, as suggested by the findings of Zhang et al. (2018b) showing a relationship between relative consumption rates and the $\mathrm{C}: \mathrm{N}$ and $\mathrm{C}: \mathrm{P}$ ratios of animal and plant food items offered to amphipods and gastropods. If the $\mathrm{C}: \mathrm{N}$ ratios of the food items offered are relatively close, individuals may need to perform larger dietary shifts to efficiently achieve nutritional balance. While the magnitude of the assimilation shifts was similar, the net increase in the C:N ratio of the snails' diet (SHW: 6\%; LHW: 9\%) was not as high as in the previous studies (10-90\%). The C:N ratios of the diets offered to the snails differed only by a factor of two (Table 1), whereas in the two other studies there was a three to sevenfold difference in the $\mathrm{C}: \mathrm{N}$ ratio of the food items composing the animal and plant diets. The weaker response by $R$. balthica may indicate a higher tolerance to heat waves than in tadpoles or crayfish, supporting that these extreme events impact species differently and change freshwater communities.

The increased assimilation of plant material at higher temperatures in our study is typically interpreted as increased herbivory (Lee et al., 2015; Boersma et al., 2016; Vejř́iková et al., 2016). However, the single study examining temperature-induced changes in the feeding choices of a freshwater snail (Lymnaea stagnalis, Linnaeus 1758) 
315 found no evidence for dietary shifts (Zhang et al., 2018a). The seemingly contradictory

316 findings in the two studies suggest that temperature effects on ectotherm feeding

317 preferences could be species-specific or may simply reflect differences in the thermal

318 sensitivity of the two model species. Additionally, the difference in the methodologies

319 used may have also contributed to this contradiction. Owing to the impracticality of

320 obtaining reliable consumption rates in a small-sized species, we used stable isotopes

321 analysis to estimate assimilation rates. Mismatches between consumption and

322 assimilation are known to occur (Schmidt et al., 2017) and could be amplified or partially

323 modulated by temperature, as the greater feeding and gut passage rates at higher

324 temperatures may increase the relative assimilation efficiency of plant diets (Myrick \&

325 Cech, 2000; Seifert et al., 2014). Although we cannot disentangle the contribution of the

326 two pathways (consumption and assimilation), our results support temperature to

327 modulate nutrient intake in $R$. balthica and a greater dependence on plant material at

328 higher temperatures. Future studies should assess both feeding preferences and

329 assimilation to determine their role in mediating temperature-induced changes in

330 ectotherm nutrient intake.

Performance on animal and plant diets

The higher performance on the plant diet, in terms of growth and reproduction,

334 supports the diet assimilation results. Despite the substantial contribution of animal

335 material, $R$. balthica snails on the mixed diet were closer to the herbivory end of the omnivory gradient, with plant material contributing to ca. $70 \%$ of their isotopic signature.

337 Previous studies found diet $\times$ temperature interactions supporting higher temperatures to decrease performance on animal diets and to increase performance on plant diets

339 (Boersma et al., 2016; Carreira et al., 2016, 2017; Malzahn et al., 2016). However, we 
340 found no evidence for the performance of the snails on the single diets to change across

341 the temperature regimes. Our experimental setup aimed to compare the effects of short 342 and uncommonly long heat waves, replicating spring conditions. Thus, the thermal contrast provided $\left(5^{\circ} \mathrm{C}\right)$ may have been insufficient to detect changes in the relative

344 performance of the diets, especially for temperatures close the species preferred thermal 345 range $-16-20^{\circ} \mathrm{C}$ in Icelandic populations (Johansson et al., 2016; Johansson \& Laurila, 2017). The reduction in oviposition observed in the snails on the plant diet in SHW could be interpreted as a cost of the acclimation to the short heat wave. However, it resulted from fewer snails reproducing throughout the experiment, rather than from fewer oviposited eggs after snails experienced the short heat wave. Thus, we cannot link the short heat wave to any direct effect on the reproduction of snails on the plant diet. We used data from the snails alive at the end of the experiment and it is possible that random variation in the number of reproducing snails, together with a small sample size $(N=11)$, may be responsible for the interaction found in SHW.

Heat wave effects on dietary shifts and life history traits

Generally, the two heat waves had similar effects, with the long heat wave prompting stronger responses in $R$. balthica. The increases in the assimilation of plant material on the mixed diet and in the overall snail growth rate were substantially larger populations of $R$. balthica, indicating failure of reproduction at $24^{\circ} \mathrm{C}$ (Johansson et al., 2016). The increased growth rate in the heat waves, together with the apparent reduction in fecundity, could suggest a trade-off between these traits, not observed in other 364 freshwater snails (Leicht et al., 2013). The positive relationship between size and 
365 fecundity supports that allocating resources to growth, by temporarily reducing 366 reproduction under heat waves, could potentially increase snail fecundity in the adult 367 stage. Thus, close to the minimum reproductive size, $R$. balthica snails may have maximized fitness by postponing reproduction to a larger size during optimal growth conditions. However, such a trade-off could prove non-adaptive over prolonged periods. Heat wave effects on fitness related traits of freshwater snails have been reported in L. stagnalis (Leicht et al., 2013, 2017). This species increased growth and reproduction under heat wave conditions, while their immune defences were reduced (Leicht et al., 2013, 2017). Phenotypic plasticity was also evident in $R$. balthica, with the relatively stronger effects of the short heat wave on plant material assimilation and growth rate snails deployed the equivalent to $60 \%$ of the plastic responses observed in the snails under heat wave conditions for seven weeks. Heat waves have been proposed to affect survival, behaviour and life history traits in non-linear ways (Chiu et al., 2014), but the responses to the short heat wave were particularly strong. Although snails in LHW should be close to isotopic equilibrium at the end of the experiment, snails in SHW are unlikely to have reached the half-life values for ${ }^{13} \mathrm{C}$ and ${ }^{15} \mathrm{~N}$ turnover rates (13 days), even when accounting for weight gain during the short heat wave (9\%). Likely underestimating the assimilation of plant material in SHW, our results suggest a larger assimilation shift in SHW than in LHW. As negative effects on performance get pronounced under prolonged heat waves (Leicht et al., 2013), snails may have been unable to sustain the strong assimilation shift implicit in SHW for a long period, reducing the assimilation of plant material as they acclimated to heat wave conditions in LHW. 

experimental setup, which could have buffered the effects of high daytime temperatures and helped snails to recover from the thermal stress (Davis et al., 2006; Putnam et al., 2010). While our results may overestimate the strength of $R$. balthica's responses in nature, this may be only partially true. We tested the effects of spring heat waves, characterized by relatively mild temperatures $\left(25^{\circ} \mathrm{C}\right)$ and this species occurs more frequently in semi-permanent and permanent habitats, experiencing higher temperatures and more intense heat waves during summer. Although the narrow temperature range tested here may prevent generalizations, it showed strong responses to small changes in temperature that otherwise may have been masked or replaced by responses to extreme temperatures. For instance, acute heat stress may increase the demand for nitrogen used in the synthesis of heat shock proteins (Podrabsky \& Somero, 2004; Lemoine et al., 2013).

\section{CONCLUSIONS} organisms with a greater challenge than changes in mean climatic conditions (Easterling, 2000; Chapman et al., 2014; Vasseur et al., 2014). As climate change progresses and the severity of heat waves increases, phenotypic plasticity may prove determinant for immediate and effective responses. Although diet regulation and changes in life history traits may help omnivore ectotherms to cope with short-term thermal stress from heat waves, drastic changes may be unsustainable over long periods. The greater dependence on plants diets at higher temperatures underscores the potential for warming and heat waves to alter trophic interactions, threatening the stability of ectotherm-dominated ecosystems like freshwaters. While individuals may experience heat waves only briefly

414 in the lifecycle, their responses are likely to have cascading effects, as feeding behavior 
415 is key in shaping the structure and functioning of communities and food webs (Kortsch 416 et al., 2015). Understanding how the multiple temperature effects on metabolism, growth

417 and intake impact nutritional requirements under normal and extreme physiological conditions will be critical to assess the ecological effects of climate change on ectotherms.

\section{ACKNOWLEDGEMENTS}

We thank previous reviewers for their insightful comments, which helped to greatly improve the manuscript. We also thank V. Baptista and A. Conde for their dedication to the project. Snail collection was carried out under permit no. 211/2014/CAPT from the Portuguese Institute for Conservation of Nature and Forests (ICNF). Animal handling and experimentation procedures were approved by the Body for Regulation of Animal Welfare (Faculty of Sciences, University of Lisbon). The study was funded by FCT - Fundação para a Ciência e a Tecnologia (Portugal), through the project EXPL_BIA-ANM_0932_2012. B.M.C. benefited from a doctoral fellowship from FCT (SFRH/BD/80341/2011) and support from the University of South Bohemia, 430 Faculty of Science, Dept. of Ecosystem Biology and Soil and Water Research Infrastructure (MEYS; projects LM2015075, EF16 013/0001782 - SoWa Ecosystems Research). P.S. was supported by the FCT IF Researcher Programme (IF/01304/ 2015). C.E.F. research unit was funded by FCT (UID/AGR/00239/2013).

DATA AVAILABILITY STATEMENT

436 The data that support the findings of this study are available from the corresponding 437 author upon reasonable request. 
The authors declare that they have no conflict of interest.

441

442

\section{REFERENCES}

443

Acheampong, E., I. Hense, \& M. A. St. John, 2014. A model for the description of

444 feeding regulation by mesozooplankton under different conditions of temperature and

445 prey nutritional status. Ecological Modelling 272: 84-97.

446

447

Anderson, T. R., D. O. Hessen, M. Boersma, J. Urabe, \& D. J. Mayor, 2017. Will

448

invertebrates require increasingly carbon-rich food in a warming world? The American

449

Naturalist 190: 725-742.

450

451

Angilletta, M. J., 2009. Thermal adaptation: A theoretical and empirical synthesis.

452

Oxford University Press, Oxford.

453

454

Arambourou, H., I. S. Villar, \& R. Stoks, 2017. Wing shape- mediated carry- over

455

effects of a heat wave during the larval stage on post- metamorphic locomotor ability.

456

Oecologia 184: 279-291.

457

458

Boersma, M., K. A. Mathew, B. Niehoff, K. L. Schoo, R. M. Franco-Santos, \& C. L.

459

Meunier, 2016. Temperature driven changes in the diet preference of omnivorous

460

copepods: No more meat when it's hot? Ecology Letters 19: 45-53.

461

462 Boukal, D. S., A. Bideault, B. M. Carreira, \& A. Sentis, 2019. Species interactions

under climate change: connecting kinetic effects of temperature on individuals to

464 community dynamics. Current Opinion in Insect Science 35: 88-95. 
466 Carreira, B. M., 2017. Frog and toad larvae become vegetarian when it is hot.

467 Temperature 4: 117-119.

468

469 Carreira, B. M., P. Segurado, A. Laurila, \& R. Rebelo, 2017. Can heat waves change the 470 trophic role of the world's most invasive crayfish? Diet shifts in Procambarus clarkii.

471 PLoS ONE 12: e0183108.

472

473 Carreira, B. M., P. Segurado, G. Orizaola, N. Gonçalves, V. Pinto, A. Laurila, \& R.

474 Rebelo, 2016. Warm vegetarians? Heat waves and diet shifts in tadpoles. Ecology 97:

$475 \quad 2964-2974$.

476

477 Chapman, S., K. Mustin, A. R. Renwick, D. B. Segan, D. G. Hole, R. G. Pearson, \& J.

478 E. M. Watson, 2014. Publishing trends on climate change vulnerability in the

479 conservation literature reveal a predominant focus on direct impacts and long time-

480 scales. Diversity and Distributions 20: 1221-1228.

481

482 Chiu, M. C., J. J. Kuo, \& M. H. Kuo, 2014. Life stage-dependent effects of

experimental heat waves on an insect herbivore. Ecological Entomology 40: 175-181.

484

485 Christidis, N., G. S. Jones, \& P. A. Stott, 2015. Dramatically increasing chance of

extremely hot summers since the 2003 European heatwave. Nature Climate Change 5:

487 $46-50$.

488

489 Clissold, F. J., N. Coggan, \& S. J. Simpson, 2013. Insect herbivores can choose 
microclimates to achieve nutritional homeostasis. The Journal of Experimental Biology 216: 2089-2096.

492

493

Clusella-Trullas, S., T. M. Blackburn, \& S. L. Chown, 2011. Climatic predictors of

494

temperature performance curve parameters in ectotherms imply complex responses to

495 climate change. The American Naturalist 177: 738-751.

496

497

Croll, S. L., \& S. A. Watts, 2004. The effect of temperature on feed consumption and 498 nutrient absorption in Procambarus clarkii and Procambarus zonangulus. Journal of the 499 World Aquaculture Society 35: 478-488.

500

501

Cross, W. F., J. M. Hood, J. P. Benstead, A. D. Huryn, \& D. Nelson, 2015. Interactions 502 between temperature and nutrients across levels of ecological organization. Global 503 Change Biology 21: 1025-1040.

504

505

Dasari, H. P., I. Pozo, F. Ferri-Yáñez, \& M. B. Araújo, 2014. A regional climate study 506 of heat waves over the Iberian Peninsula. Atmospheric and Climate Sciences 4: 841507 853.

508

509 Davis, J. A., E. B. Radcliffe, \& D. W. Ragsdale, 2006. Effects of high and fluctuating 510 temperatures on Myzus persicae (Hemiptera: Aphididae). Environmental Entomology 35: 1461-1468.

512

513 Diffenbaugh, N. S., \& C. B. Field, 2013. Changes in ecologically critical terrestrial 514 climate conditions. Science 341: 486-492. 
516 Dinh, K. V., L. Janssens, \& R. Stoks, 2016. Exposure to a heat wave under food

517 limitation makes an agricultural insecticide lethal: a mechanistic laboratory experiment.

518 Global Change Biology 22: 3361-3372.

519

520 Dobush, G. R., C. D. Ankney, \& D. G. Krementz, 1985. The effect of apparatus, extraction time, and solvent type on lipid extractions of snow geese. Canadian Journal of Zoology 63: 1917-1920.

523

524 Dowd, W. W., F. A. King, \& M. W. Denny, 2015. Thermal variation, thermal extremes and the physiological performance of individuals. Journal of Experimental Biology 218: $1956-1967$.

527

528

Easterling, D. R., 2000. Climate extremes: observations, modeling, and impacts.

529 Science 289: 2068-2074.

530

531

Elser, J. J., D. R. Dobberfuhl, N. A. MacKay, \& J. H. Schampel, 1996. Organism size, 532 life history, and N:P stoichiometry. BioScience 46: 674-684.

533

534 Emde, S., J. Kochmann, T. Kuhn, D. D. Dörge, M. Plath, F. W. Miesen, \& S. Klimpel, 535 2016. Cooling water of power plant creates "hot spots" for tropical fishes and parasites. 536 Parasitology Research 115: 85-98.

537

538 Fischer, K., M. Klockmann, \& E. Reim, 2014. Strong negative effects of simulated heat 539 waves in a tropical butterfly. The Journal of Experimental Biology 217: 2892-2898. 
541 Floeter, S. R., M. D. Behrens, C. E. L. Ferreira, M. J. Paddack, \& M. H. Horn, 2005.

542 Geographical gradients of marine herbivorous fishes: patterns and processes. Marine

543 Biology 147: 1435-1447.

544

545 Forster, J., A. G. Hirst, \& G. Woodward, 2011. Growth and development rates have 546 different thermal responses. The American Naturalist 178: 668-678.

547

548 Frich, P., L. V. Alexander, P. Della-Marta, B. Gleason, M. Haylock, A. M. G. Tank

549 Klein, \& T. Peterson, 2002. Observed coherent changes in climatic extremes during the 550 second half of the twentieth century. Climate Research 19: 193-212.

551

552 Garrabou, J., R. Coma, N. Bensoussan, M. Bally, P. Chevaldonné, M. Cigliano, D.

553 Diaz, J. G. Harmelin, M. C. Gambi, D. K. Kersting, J. B. Ledoux, C. Lejeusne, C.

554 Linares, C. Marschal, T. Pérez, M. Ribes, J. C. Romano, E. Serrano, N. Teixido, O.

555 Torrents, M. Zabala, F. Zuberer, \& C. Cerrano, 2009. Mass mortality in Northwestern

556 Mediterranean rocky benthic communities: effects of the 2003 heat wave. Global

557 Change Biology 15: 1090-1103.

558

559 Ghalambor, C. K., J. K. McKay, S. P. Carroll, \& D. N. Reznick, 2007. Adaptive versus 560 non-adaptive phenotypic plasticity and the potential for contemporary adaptation in new 561 environments. Functional Ecology 21: 394-407.

562

563 Gillooly, J. F., J. H. Brown, G. B. West, V. M. Savage, \& E. L. Charnov, 2001. Effects 564 of size and temperature on metabolic rate. Science 293: 2248-2252. 
566 Giorgi, F., 2006. Climate change hot-spots. Geophysical Research Letters 33: 1-4.

567

568 González-Bergonzoni, I., E. Jeppesen, N. Vidal, F. Teixeira-de Mello, G. Goyenola, A.

569 López-Rodríguez, \& M. Meerhoff, 2016. Potential drivers of seasonal shifts in fish

570 omnivory in a subtropical stream. Hydrobiologia 768: 183-196.

571

572 González-Bergonzoni, I., M. Meerhoff, T. A. Davidson, F. Teixeira-de Mello, A.

573 Baattrup-Pedersen, \& E. Jeppesen, 2012. Meta-analysis shows a consistent and strong

574 latitudinal pattern in fish omnivory across ecosystems. Ecosystems 15: 492-503.

575

576 Guinan Jr, M. E., K. L. Kapuscinski, \& M. A. Teece, 2015. Seasonal diet shifts and

577 trophic position of an invasive cyprinid, the rudd Scardinius erythrophthalmus

578 (Linnaeus, 1758), in the upper Niagara river. Aquatic Invasions 10: 217-225.

579

580 Jeppesen, E., M. Meerhoff, K. Holmgren, I. González-Bergonzoni, F. Teixeira-de

581 Mello, S. A. J. Declerck, L. De Meester, M. Sondergaard, T. L. Lauridsen, R. Bjerring,

582 J. M. Conde-Porcuna, N. Mazzeo, C. Iglesias, M. Reizenstein, H. J. Malmquist, Z. Liu,

583 D. Balayla, \& X. Lazzaro, 2010. Impacts of climate warming on lake fish community

584 structure and potential effects on ecosystem function. Hydrobiologia 646: 73-90.

585

586 Jerez, S., J. P. Montavez, J. J. Gomez-Navarro, R. Lorente-Plazas, J. A. Garcia-Valero,

$587 \&$ P. Jimenez-Guerrero, 2013. A multi-physics ensemble of regional climate change

588 projections over the Iberian Peninsula. Climate Dynamics 41: 1749-1768. 
590

591

592

593

594

595

596

597

598

599

600

601

602

603

604

605

606

607

608

609

610

611

612 Kutz, T. C., C. M. Sgrò, \& C. K. Mirth, 2019. Interacting with change: diet mediates

613

Jiguet, F., A. S. Gadot, R. Julliard, S. E. Newson, \& D. Couvet, 2007. Climate

envelope, life history traits and the resilience of birds facing global change. Global

Change Biology 13: 1672-1684.

Johansson, M. P., F. Ermold, B. K. Kristjánsson, \& A. Laurila, 2016. Divergence of gastropod life history in contrasting thermal environments in a geothermal lake. Journal of Evolutionary Biology 29: 2043-2053.

Johansson, M. P., \& A. Laurila, 2017. Maximum thermal tolerance trades off with chronic tolerance of high temperature in contrasting thermal populations of Radix balthica. Ecology and Evolution 7: 3149-3156.

Karl, I., \& K. Fischer, 2008. Why get big in the cold? Towards a solution to a lifehistory puzzle. Oecologia 155: 215-225.

Kingsolver, J. G., \& H. A. Woods, 1997. Thermal sensitivity of growth and feeding in Manduca sexta caterpillars. Physiological Zoology 70: 631-638.

Kortsch, S., R. Primicerio, M. Fossheim, A. V Dolgov, \& M. Aschan, 2015. Climate change alters the structure of arctic marine food webs due to poleward shifts of boreal generalists. Proceedings of the Royal Society B 282: 20151546. how larvae respond to their thermal environment. Functional Ecology 0: 1-12. 
Lee, K. P., T. Jang, N. Ravzanaadii, \& M. S. Rho, 2015. Macronutrient balance modulates the temperature-size rule in an ectotherm. The American Naturalist 186: $212-222$.

Lee, K. P., \& C. Roh, 2010. Temperature-by-nutrient interactions affecting growth rate in an insect ectotherm. Entomologia Experimentalis et Applicata 136: 151-163.

Leicht, K., J. Jokela, \& O. Seppälä, 2013. An experimental heat wave changes immune defense and life history traits in a freshwater snail. Ecology and Evolution 3: 48614871.

Leicht, K., K. Seppälä, \& O. Seppälä, 2017. Potential for adaptation to climate change: Family-level variation in fitness-related traits and their responses to heat waves in a snail population. BMC Evolutionary Biology 17: 140.

Lemoine, N. P., \& D. E. Burkepile, 2012. Temperature-induced mismatches between consumption and metabolism reduce consumer fitness. Ecology 93: 2483-2489.

Lemoine, N. P., W. A. Drews, D. E. Burkepile, \& J. D. Parker, 2013. Increased temperature alters feeding behavior of a generalist herbivore. Oikos 122: 1669-1678.

Ma, G., V. H. W. Rudolf, \& C.-S. Ma, 2015. Extreme temperature events alter demographic rates, relative fitness, and community structure. Global Change Biology 21: $1794-1808$. 
640

641

642

643

644

645

646

647

648

649

650

651

652

653

654

655

656

657

658

659

660

661

662

663

664

Malzahn, A. M., D. Doerfler, \& M. Boersma, 2016. Junk food gets healthier when it's warm. Limnology and Oceanography 61: 1677-1685.

Meehl, G. A., \& C. Tebaldi, 2004. More intense, more frequent, and longer lasting heat waves in the 21st Century. Science 305: 994-997.

Miller, G. A., F. J. Clissold, D. Mayntz, \& S. J. Simpson, 2009. Speed over efficiency: locusts select body temperatures that favour growth rate over efficient nutrient utilization. Proceedings of the Royal Society B 276: 3581-3589.

Mironidis, G. K., \& M. Savopoulou-Soultani, 2010. Effects of heat shock on survival and reproduction of Helicoverpa armigera (Lepidoptera: Noctuidae) adults. Journal of Thermal Biology 35: 59-69.

Myrick, C. A., \& J. J. Cech, 2000. Temperature influences on California rainbow trout physiological performance. Fish Physiology and Biochemistry 22: 245-254.

Paaijmans, K. P., R. L. Heinig, R. A. Seliga, J. I. Blanford, S. Blanford, C. C. Murdock, \& M. B. Thomas, 2013. Temperature variation makes ectotherms more sensitive to climate change. Global Change Biology 19: 2373-2380.

Palmer, G., P. J. Platts, T. Brereton, J. W. Chapman, C. Dytham, R. Fox, J. W. PearceHiggins, D. B. Roy, J. K. Hill, \& C. D. Thomas, 2017. Climate change, climatic variation and extreme biological responses. Philosophical Transactions of the Royal Society B 372: 20160144. 
666 Parmesan, C., 2006. Ecological and evolutionary responses to recent climate change.

667 Annual Review of Ecology, Evolution, and Systematics 37: 637-669.

668

669 Parmesan, C., \& G. Yohe, 2003. A globally coherent fingerprint of climate change

670 impacts across natural systems. Nature 421: 37-42.

671

672 Parnell, A. C., R. Inger, S. Bearhop, \& A. L. Jackson, 2010. Source partitioning using 673 stable isotopes: Coping with too much variation. PLoS ONE 5: e9672.

674

675 Parnell, A. C., D. L. Phillips, S. Bearhop, B. X. Semmens, E. J. Ward, J. W. Moore, A.

676 L. Jackson, J. Grey, D. J. Kelly, \& R. Inger, 2013. Bayesian stable isotope mixing

677 models. Environmetrics 24: 387-399.

678

Perkins, S. E., L. V. Alexander, \& J. R. Nairn, 2012. Increasing frequency, intensity and 680 duration of observed global heatwaves and warm spells. Geophysical Research Letters 681 39: $1-5$.

682

683

Persson, J., M. W. Wojewodzic, D. O. Hessen, \& T. Andersen, 2011. Increased risk of 684 phosphorus limitation at higher temperatures for Daphnia magna. Oecologia 165: 123685 129.

686

687 Pfenninger, M., M. Salinger, T. Haun, \& B. Feldmeyer, 2011. Factors and processes

688 shaping the population structure and distribution of genetic variation across the species 689 range of the freshwater snail Radix balthica (Pulmonata, Basommatophora). BMC 
691

692 Podrabsky, J. E., \& G. N. Somero, 2004. Changes in gene expression associated with 693 acclimation to constant temperatures and fluctuating daily temperatures in an annual killifish Austrofundulus limnaeus. Journal of Experimental Biology 207: 2237-2254.

695

696 Preston, T., \& N. J. P. Owens, 1983. Interfacing an automatic elemental analyser with 697 an isotope ratio mass sepectrometer: the potential for fully automated total nitrogen and 698 nitrogen-15 analysis. Analyst 108: 971-977.

699

700

Putnam, A. E., G. H. Denton, J. M. Schaefer, D. J. A. Barrell, B. G. Andersen, R. C. 701 Finkel, R. Schwartz, A. M. Doughty, M. R. Kaplan, \& C. Schlüchter, 2010. Glacier 702 advance in southern middle-latitudes during the Antarctic Cold Reversal. Nature Geoscience 3: 700-704.

704

Rendon, D., V. Walton, G. Tait, J. Buser, I. Lemos Souza, A. Wallingford, G. Loeb, \& 706 J. Lee, 2019. Interactions among morphotype, nutrition, and temperature impact fitness 707 of an invasive fly. Ecology and Evolution 9: 2615-2628.

708

Rho, M. S., \& K. P. Lee, 2017. Temperature-driven plasticity in nutrient use and preference in an ectotherm. Oecologia 185: 401-413.

711

712 Rosenblatt, A. E., \& O. J. Schmitz, 2016. Climate change, nutrition, and bottom-up and top-down food web processes. Trends in Ecology and Evolution 31: 965-975. 
Roth, O., J. Kurtz, \& T. B. H. Reusch, 2010. A summer heat wave decreases the immunocompetence of the mesograzer, Idotea baltica. Marine Biology 157: 1605-

717 1611

718

719 Schär, C., P. L. Vidale, D. Luthi, C. Frei, C. Haberli, M. A. Liniger, \& C. Appenzeller, 720 2004. The role of increasing temperature variability in European summer heatwaves. Nature 427: 332-336.

722

723

Schmidt, K., M. L. Blanchette, R. G. Pearson, R. A. Alford, \& A. M. Davis, 2017.

724

Trophic roles of tadpoles in tropical Australian streams. Freshwater Biology 62: 19291941.

726

727

Schmitz, O. J., A. E. Rosenblatt, \& M. Smylie, 2016. Temperature dependence of 728 predation stress and the nutritional ecology of a generalist herbivore. Ecology 97: 3119729 3130.

730

731

Seifert, L. I., F. De Castro, A. Marquart, U. Gaedke, G. Weithoff, \& M. Vos, 2014.

732

Heated relations: Temperature-mediated shifts in consumption across trophic levels. PLoS ONE 9: e95046.

Sentis, A., J. L. Hemptinne, \& J. Brodeur, 2013. Effects of simulated heat waves on an 736 experimental plant-herbivore-predator food chain. Global Change Biology 19: 833-842.

737 waves and predators on prey phenotype and transgenerational phenotypic plasticity. 
Global Change Biology 23: 4598-4608.

741

742 Stoks, R., J. Verheyen, M. Van Dievel, \& N. Tüzün, 2017. Daily temperature variation and extreme high temperatures drive performance and biotic interactions in a warming world. Current Opinion in Insect Science 23: 35-42.

745

746

747 animal kingdom: a synthesis of existing data. Journal of Animal Ecology 84: 861-870.

748 20132612.

753

754 herbivorous fish is frozen by low temperature. Scientific Reports 6: 39600 .

757

758 ecosystems: impacts across multiple levels of organization. Philosophical Transactions of the Royal Society B 365: 2093-2106. 
765 Zhang, P., B. A. Blonk, R. F. van den Berg, \& E. S. Bakker, 2018a. The effect of

766 temperature on herbivory by the omnivorous ectotherm snail Lymnaea stagnalis.

767 Hydrobiologia 812: 147-155.

768

769 Zhang, P., R. F. Van Den Berg, C. H. A. Van Leeuwen, B. A. Blonk, \& E. S. Bakker,

7702018 b. Aquatic omnivores shift their trophic position towards increased plant

771 consumption as plant stoichiometry becomes more similar to their body stoichiometry.

772 PLoS ONE 13: e0204116.

773 
775

776 Table 1. Isotopic signature and elemental ratio of the experimental diets (average \pm 777 standard deviation).

\begin{tabular}{|l|c|c|}
\hline & Animal diet & Plant diet \\
\hline $\boldsymbol{\delta}^{{ }^{13}} \mathbf{C}$ & $-24.61 \pm 0.13$ & $-27.79 \pm 0.12$ \\
\hline $\boldsymbol{\delta}^{\mathbf{1 5}} \mathbf{N}$ & $5.09 \pm 0.92$ & $0.42 \pm 1.01$ \\
\hline $\mathbf{C}: \mathbf{N}$ & $3.79 \pm 0.05$ & $6.55 \pm 0.71$ \\
\hline
\end{tabular}

778

779

780 Table 2. General linear model for growth rate and generalized linear model for 781 reproduction (negative binomial distribution).

\begin{tabular}{|l|c|c|c|c|c|c|}
\hline & \multicolumn{3}{|c|}{ Growth } & \multicolumn{3}{c|}{ Reproduction } \\
\hline Factors & $d f$ & $\mathrm{~F}$ & $P$ & $d f$ & $\chi^{2}$ & $P$ \\
\hline Diet & 2,68 & 5.29 & $<0.01^{*}$ & 2,68 & 11.71 & $<0.01^{*}$ \\
\hline Temperature & 2,68 & 3.94 & $<0.05^{*}$ & 2,68 & 3.23 & 0.199 \\
\hline Diet $\times$ Temperature & 4,68 & 1.49 & 0.216 & 4,68 & 10.97 & $<0.05^{*}$ \\
\hline
\end{tabular}

*Denotes $P$ values $<0.05$ 
FIGURE CAPTIONS

784

785 Fig. 1 Temperature variation over time in the experimental treatments

786

787 Fig. 2 Proportion of plant material assimilated (a), LN of growth rate in $\mathrm{mg}^{-d a y^{-1}}$ (b) and 788 total number of oviposited eggs (c) on animal (grey), plant (white) and mixed diets 789 (black). Boxes show the median and the $25^{\text {th }}-75^{\text {th }}$ percentiles and whiskers indicate the $7902.5^{\text {th }}-97.5^{\text {th }}$ percentiles (a) or the minimum and maximum (b,c). Significant contrasts are 791 depicted with different letters 
Figure 1.

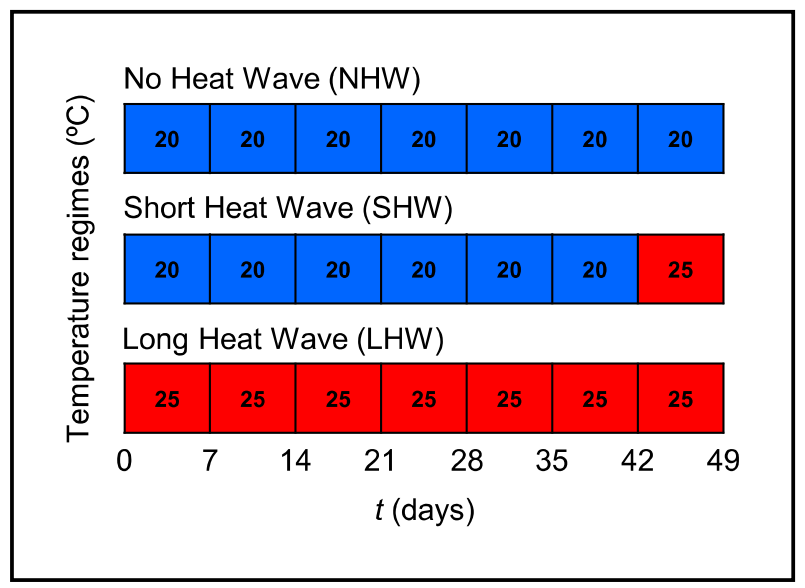


Figure 2.

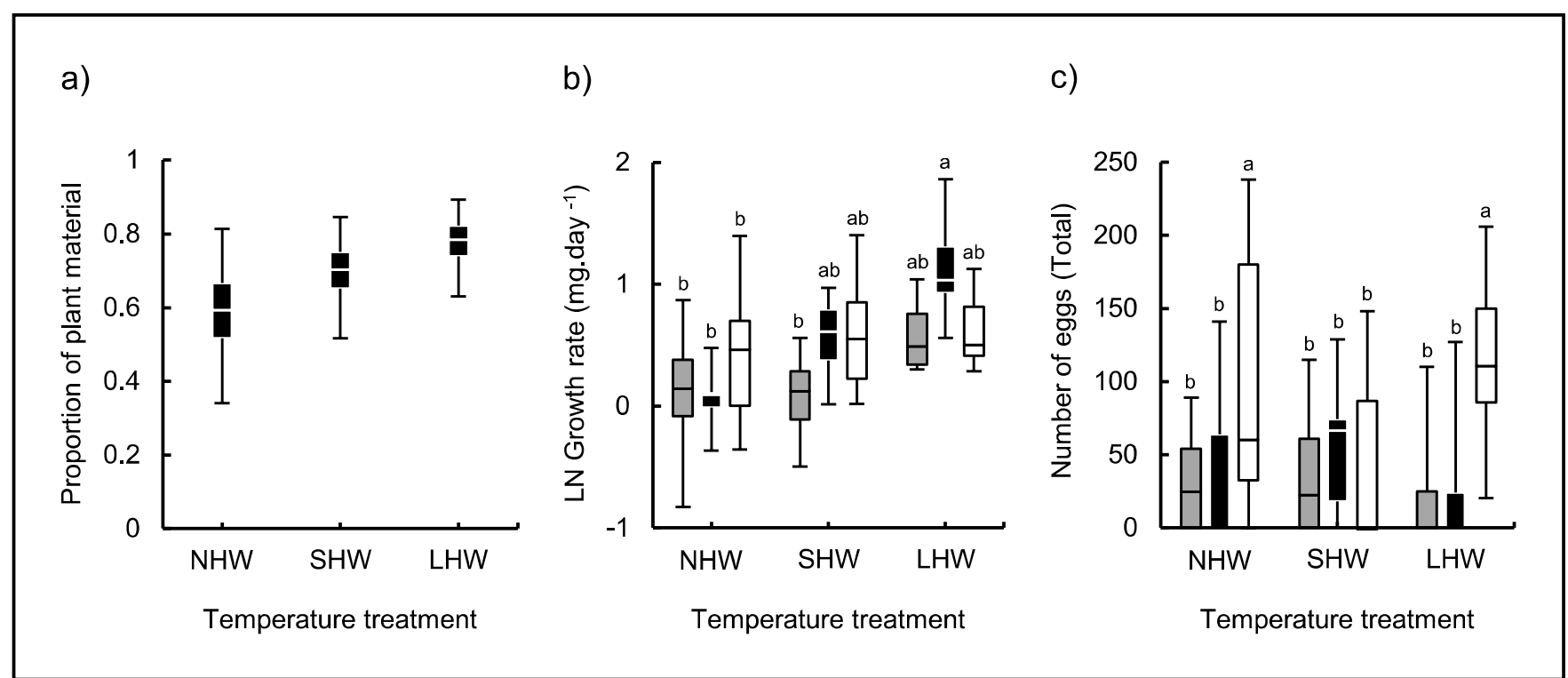

